\title{
Гришкина T.E.
}

\section{Методика решения исследовательских задач бакалавров психологов с применением F-критерия Фишера}

ФГБОУ ВО «Амурский государственный университет» (Россия, Благовещенск)

doi: $10.18411 / l j-02-2021-130$

idsp: ljournal-02-2021-130

\section{Аннотация}

В статье представлена актуальность решения исследовательских задач бакалавров психологов в рамках учебного процесса, в частности, при изучении темы «Параметрические критерии». Рассмотрена методика решения задачи с помощью Fкритерия Фишера. Приведены основные ограничения по использованию данного критерия.

Ключевые слова: исследовательские задачи, параметрический критерий, Fкритерий Фишера

\section{Abstract}

The article presents the relevance of solving research problems of bachelors of psychologists within the educational process, in particular, when studying the topic Parametric criteria. The technique of solving the problem using Fisher's F-criterion is considered. The main restrictions on the use of this criterion are given.

Keywords: research problems, parametric criteria, Fisher's F-criterion

Интеграция исследовательских профессиональных задач в процесс обучения является неотьемлемой частью подготовки будущего бакалавра психолога.

При проведении психолого-педагогического исследования будущий бакалавр решает аналитические, диагностические, прогностические, проективные, рефлексивные исследовательские профессиональные задачи [1].

К исследовательским задачам, решаемым с помощью методов математической статистики, можно отнести следующие: выявление различий в уровне исследуемого признака, оценка сдвига значений исследуемого признака, выявление различий в распределении признака, выявление степени согласованности изменений, анализ изменений признака под влиянием контролируемых условий.

В учебный план направления подготовки 37.03.01 - Психология включена дисциплина «Математические методы в психологии», содержание которой предусматривает изучение темы «Параметрические критерии».

Ограничениями для применения этих критериев являются: подчинение выборочных данных нормальному закону распределения, работа только с количественными данными.

Рассмотрим методику решения задачи с использованием параметрических критериев, в частности, F-критерия Фишера.

Данный критерий используется в задачах для сравнения величины выборочных дисперсий двух рядов наблюдений.

Следует обратить внимание, что в формулировке практической задачи, при решении которой применяется критерий Фишера, встречаются, например, такие вопросы: есть ли различия в степени однородности исследуемого признака в двух выборках; можно ли считать, что разброс значений признака в выборках одинаков (различен).

Прежде чем решать задачи на практических занятиях, следует изучить теоретический материал по данной теме. Так как эмпирические данные, как правило, являются выборкой из некоторой генеральной совокупности, то обязательное условие - 
проверка значимости полученного критерия с помощью метода проверки статистических гипотез.

Задача. В двух начальных классах школы психолог проводил тестирование умственного развития по тесту умственного развития младших школьников. При проверке гипотез о равенстве средних с помощью критерия Стьюдента был получен результат: достоверных различий нет (уровень значимости $\alpha=0,05$ ). Психолога интересует вопрос - есть ли различия в степени однородности данного признака? (уровень значимости $\alpha=0,05$ )

Таблийа 1

Результаты тестирования

\begin{tabular}{|c|c|c|c|c|c|c|c|c|c|c|c|c|}
\hline № учащихся & 1 & 2 & 3 & 4 & 5 & 6 & 7 & 8 & 9 & 10 & сумма & среднее \\
\hline класс 1 (х) & 79 & 88 & 34 & 40 & 29 & 90 & 39 & 79 & 75 & 53 & 606 & 60,6 \\
\hline класс 2 (у) & 62 & 64 & 87 & 49 & 72 & 65 & 63 & 56 & 77 & 41 & 636 & 63,6 \\
\hline
\end{tabular}

При анализе условия задачи, обратим внимание на следующие моменты: был проведен статистический анализ представленных данных, и подтвердилась гипотеза о равенстве средних; проверка гипотез осуществлялась с помощью критерия Стьюдента, который тоже является параметрическим критерием. Отсюда следует, что выборочные данные подчиняются нормальному закону распределения, и проверять выборки на нормальность уже не требуется. Также, в условии присутствует формулировка вопроса, которая указывает на возможность применения в статистической обработке результатов данного исследовании F-критерия Фишера.

Решение:

Вычислим выборочные дисперсии для х и у (средние значения по каждой выборке, представлены в таблице 1) по формулам:

$$
\begin{aligned}
& S_{x}^{2}=\frac{1}{n_{1}-1} \sum(x-\bar{x})^{2}, S_{y}^{2}=\frac{1}{n_{2}-1} \sum(y-\bar{y})^{2}, \\
& S_{x}^{2}=\frac{1}{10-1}\left[(79-60,6)^{2}+(88-60,6)^{2}+(34-60,6)^{2}+\ldots+(75-60,6)^{2}+(53-60,6)^{2}\right]= \\
& =572,83 \\
& S_{y}^{2}=\frac{1}{10-1}\left[(62-63,6)^{2}+(64-63,6)^{2}+\ldots+(77-63,6)^{2}+(41-63,6)^{2}\right]= \\
& =174,04
\end{aligned}
$$

Выдвинем основную и конкурирующую гипотезы:

$\mathrm{H}_{0}: S_{x}^{2}=S_{y}^{2}-$ различия в степени однородности показателя умственного развития в классах отсутствуют.

$\mathrm{H}_{1}: \quad S_{x}^{2} \neq S_{y}^{2}-$ присутствуют статистически значимые различия в степени однородности показателя умственного развития в классах.

Наблюдаемое значение F-критерия Фишера рассчитаем по формуле:

$$
F_{\text {набл }}=\frac{S_{x}^{2}}{S_{y}^{2}},
$$

где $S_{x}^{2}$ - большая по величине выборочная дисперсия, $S_{y}^{2}$ - меньшая по величине выборочная дисперсия [3, с. 175].

$F_{\text {набл }}=\frac{572,83}{174,04}=3,29$

По таблице для F-критерия Фишера и числа степеней свободы $d f_{1}=n_{1}-1=10-1=9, d f_{2}=n_{2}-1=10-1=9$ найдем $F_{\text {крит }}$ : 


$$
F_{\text {крит }}=3,18, \text { для } \alpha=0,05 \text {. }
$$

По условию уровень значимости только $\alpha=0,05$, следовательно, на оси присутствуют зона значимости (область принятия альтернативной гипотезы), зона незначимости (область принятия нулевой гипотезы), а зона неопределенности отсутствует.

Отметим на оси значимости критические значения, выделим соответствующие зоны, отметим наблюдаемое значение критерия:

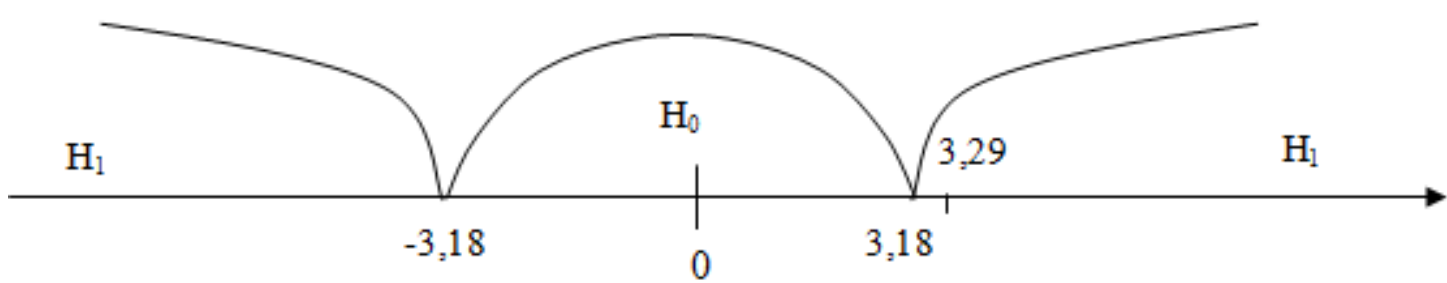

Рис. 1. Ось значимости

Так как $F_{\text {набл }}>F_{\text {крит }}$, то полученная величина попала в зону значимости, в терминах статистических гипотез можно утверждать, что гипотеза $\mathrm{H}_{0}$ отвергается, a принимается гипотеза $\mathrm{H}_{1}$, то есть присутствуют различия в степени однородности показателя умственного развития в классах.

Реализация решения задач с применением параметрических критериев возможна и на лабораторных занятиях с помощью статистических программ: Statistica, SPSS Statistics.

Сформулируем краткий алгоритм решения исследовательской задачи с применением F-критерия Фишера в программе Statistica:

1. Создаем файл с двумя переменными (Var1, Var2), вносим результаты эксперимента.

2. Выбираем проверку с помощью t-критерия Стьюдента для независимых выборок.

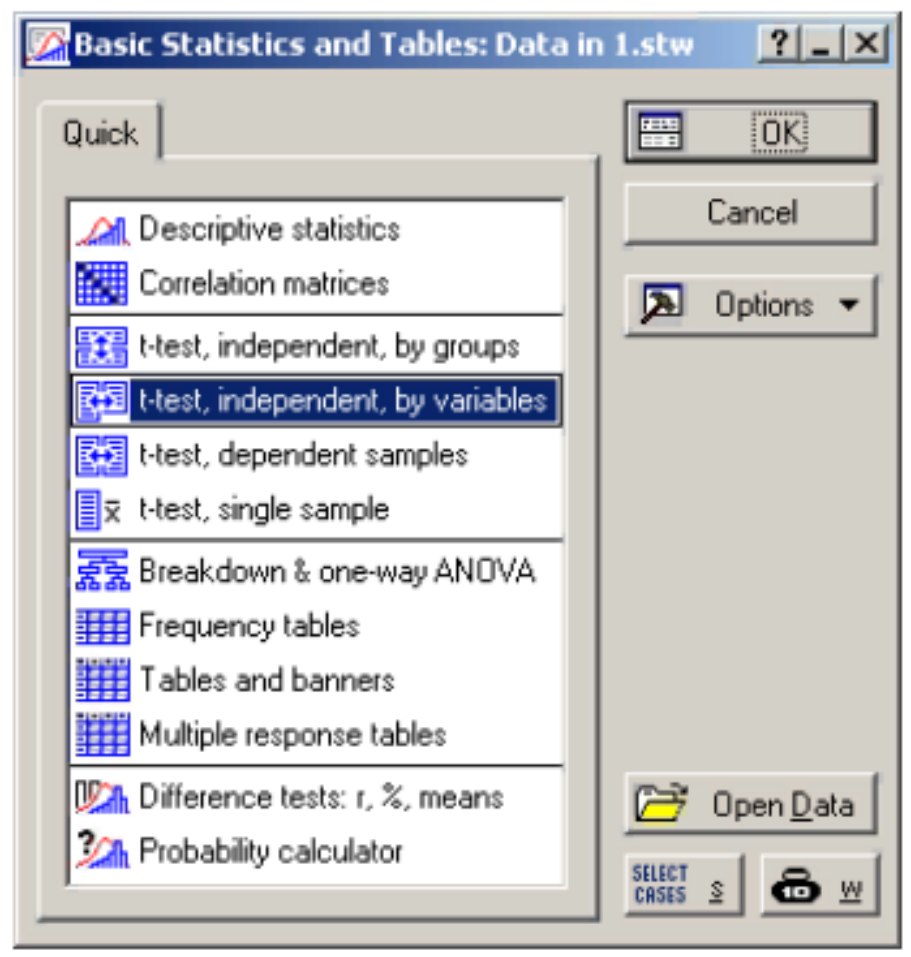

Pис. 2. t-test для независимых выборок 
3. Выбираем переменные и нажимаем Summary, программой производится подсчет значений среднеквадратичных отклонений и критерия Фишера.

4. С помощью вероятностного калькулятора (Probability calculator) находим критические значения и по полученным результатам делаем вывод о принятии нулевой или альтернативной гипотезы.

F-критерий можно использовать для сравнения дисперсий и более чем двух совокупностей, например, в однофакторном дисперсионном анализе [2].

Представленная методика решения исследовательской задачи не является универсальной, однако, для большинства исследовательских задач бакалавров психологов основной алгоритм решения: выдвижение гипотез, вычисление критерия, проверка критерия на значимость, остается неизменным.

\section{$* * *$}

1. Гришкина Т.Е., Юрьева Т.А. Качественные и количественные методы исследования в решении профессиональных задач бакалавров психолого-педагогического образования // Теория и практика общественного развития. - 2014. №5. - С. 87-90.

2. Гришкина Т.Е. Однофакторный дисперсионный анализ в прикладных задачах бакалавров психологов // Вопросы педагогики. - 2020. - № 5-2. - С. 102-106.

3. Ермолаев О.Ю. Математическая статистика для психологов: учебник / О.Ю. Ермолаев. - 3-е изд., испр. - М.: Московский психолого-социальный институт: Флинта, 2004. - 336 с.

\section{Гулякин Д.В. \\ Требования к профессиональной подготовке современного инженера}

Кубанский государственный технологический университет (Россия, Краснодар)

doi: $10.18411 / l j-02-2021-131$

idsp: ljournal-02-2021-131

Аннотация

В статье рассмотрены социально-информационные аспекты требований к профессиональной деятельности современных инженеров в контексте развития современного общества.

Ключевые слова: инженер, требования работодателей, социальноинформационная культура.

\section{Abstract}

The article deals with the social and information aspects of the requirements for the professional activity of modern engineers in the context of the development of modern society.

Key words: engineer, employer's requirements, social and information culture.

В России почти каждый четвертый житель страны имеет техническое и инженерное образование. В то же время обращает на себя внимание слишком большое отставание от Европы по доли специалистов в естественных науках: математике, вычислительной технике, физике, и т.д. Их доля в населении России в 3,4 раза ниже, чем в Западных странах, особенно сильное отставание от Франции и Великобритании.

Здесь очевидна недооценка подготовки кадров для фундаментальных наук в последние годы, плохое финансирование и слабый приток молодежи в науку, а также влияние процессов эмиграции научной интеллигенции в последние два десятилетия.

Проблематика влияния современных тенденций на состояние инженерного образования разрабатывается в трудах Б.Л Аграновича, Б.Л. Вульфсона, О.В. Долженко, Э.Э. Исмаилова, В.А. Капрановой, А.И. Чучалина, 3.С. Сазоновой, Ю.П. Похолкова, В.Л. Шатуновского К. Ясперса и других ученых. 